\title{
Exploring the Improved Personal Credit Scoring Model of Ant Financial Services in its Disruptive Innovation Process
}

\author{
Wen-yao Zhang \\ School of Management, Harbin Institute of Technology, Harbin 150001, China
}

\begin{abstract}
Ant Financial Services, by taking cloud computing and big data as underlying facilities and credit system as basis, opens up low-end small and micro and individual customer market which is not satisfied in traditional financial market by disruptive service modes and concepts. "Sesame Credit" with unique digital credit means, aiming at accurately measuring personal credit score, is one of the key links for Ant Financial Services to carry out disruptive innovation. Sesame Credit is in open beta period, in spite of wide attention and remarkable achievement, it is still at the experimental stage with certain limitations. Thus, this paper first discloses the disruptive innovation characteristics that Ant Financial Services has, then analyses and discusses the scoring of Sesame Credit, and finally on this basis proposes an improved personal credit scoring model.

Index Terms - Ant financial services; Disruptive innovation; Sesame credit scoring; Improved personal credit scoring model.
\end{abstract}

\section{Introduction}

Internet finance market is positioned at "small and micro" level, characterized by small amount, fastness, and convenience, and it thus has outstanding advantages in the sector of small and micro finance [1]. Internet finance constantly innovates credit means by using big data mining technology to greatly reduce credit and financing costs of small and micro enterprises [2] as well as information asymmetry. The key of the healthy development of Internet finance is to deepen the credit system. The improved and perfected credit system enhances the financial risk management level and the efficiency of resource allocation, thus it better provides convenient services to low-end longtailed users in the financial market and achieves disruptive innovation in the financial sector.

Ant Financial Services subordinate to Alibaba Group, as a typical representative of Internet financial companies, establishes Sesame Credit, the China's first personal digital credit throughout history, in the support of Internet platform, cloud computing, and big data technologies. It can serve lowend micro and small and individual customer markets where cannot be satisfied in the traditional financial market. Sesame Credit is still in open beta period but has the room for improvement in the objective acquisition of data [3] as well as for improvement in the accurate scoring [4]. Therefore, this paper first discloses the disruptive innovation characteristics of Ant Financial Services, then analyses and discusses Sesame Credit scoring, and finally on this basis proposes the improved personal credit scoring model to provide reference for personal credit scoring.

\section{Analysis on Disruptive Innovation of Ant Financial Services}

Disruptive innovation is classified into low-end market disruption and new market disruption, aiming to provide consumers with "simple, convenient, inexpensive" product or service [5]. Its essence lies in creating and delivering more value to customers on the market, and this is the decisive factor to attract and retain customers. Disruptive innovations are the innovations that "disrupt an established trajectory of performance improvement, or re-define what performance means" in an industry [6]. There are two criteria to distinguish disruptive innovation from other types of innovations: First, disruptive innovation starts with inferior performance that existing customers expect, but is superior in price; Second, it evolves to become "good enough" performance while at the same time remains superior in price. These criteria embody the idea that disruptive innovation challenges the established value proposition and business models of incumbents [7].

Ant Financial Services Group (hereinafter referred to as Ant Financial Services) was built on October 16, 2014, and has been committed to realizing inclusive finance through pushing Internet finance by the application of Internet technology. It first puts forth "Sesame Credit" by using new IT technologies represented by big data and cloud computing, bringing new ideas to the construction of credit system. In essence, Ant Financial Services envisions to develop a more complete set of big data credit system that is integrated by personal financial account, social network information, and public utilities information. The credit system is capable of serving small and micro and individual groups which cannot be covered by the traditional financial institutions, thereby opening up a new low-end "nonconsumer market." In addition, it takes advantage of new IT technologies to deploy exquisite business process, to improve operational efficiency and accuracy, to optimize data processing cost, and to reduce credit information processing cost. Hence, the products and services that are provided by Ant Financial Services have the typical and outstanding characteristics of disruptive innovation .

\section{Sesame Credit Scoring Analysis}

Sesame Credit, as a credit system, launched the open beta within a small set of users on January 28, 2015, visually presenting the credit levels for users. It can be said that China has its own personal credit scoring ever since then. The data come from four sources, namely e-business data from Alibaba 
Group platform, Internet finance data from Ant Financial Services, information from many cooperative public institutions and collaborative partners, and all kinds of selfdetermined information of users. Sesame scores are affected by those data sources centering on five dimensional factors of identity traits, credit history, behavioral preferences, performance capabilities, and interpersonal connections. Sesame Credit makes references to the American personal credit scoring mechanism FICO (scoring from 300 to 850 [8] ) and sets on intervals between 350 and 950. Each interval represents a different credit level, the higher the score, the credit the better.

However, FICO scoring that has been referred by Sesame Credit though still reflects the risk order, its ability to predict the absolute risk and its performance in the financial crisis in 2008 are blamed. Three major foreign credit institutions and FICO company have made prospective study by utilizing big data technology to improve traditional credit evaluation system [9]. Moreover, as Sesame Credit has not docked with credit system of central bank, there are common problems such as dimensions selected not enough and limited data sources [10]. As can be seen from the current operation scoring results, Sesame Credit scores can be subjectively increased by users, such as by more shopping on Ali e-business platforms like Tmall, Taobao, and Juhuasuan group-buying websites, more use of Alipay credit card payment and timely payment, more use of Alipay transfers, more purchase of financial products on Alipay, more application of life services on Alipay, and more love donations [3]. Thus it can be seen the data obtained from being cooperated with Alipay and e-business of Alibaba constitute a higher weight in the credit scoring, but there is the room for improvement in terms of objective acquisition of data and accurate scoring. Consequently, this paper comes up with the improved personal credit scoring model on this basis.

\section{An Improved Personal Credit Scoring Model}

In view of the characteristics of big data technology applied, this paper puts forward the improved multilevel personal credit scoring model that consists of data processing area and data evaluation area, including five levels (see Fig. 1). Data processing area refers to the extraction of critical data for credit assessment out of a number of credit information databases by taking advantage of big data technology, and to process into the valid data formats; data evaluation area is on this basis to combine the critical data information with the professional credit knowledge, and all those information becomes an important reference basis for the credit assessment, in a way for developing the new credit products and services.

The first level is a raw data level to collect primary multidimensional credit data based on big data technology, and the horizontal expansion of data sources to data variables on the edge is to describe users and to further quantify credit assessment from different angles. Multisource data are divided into the structured data and the unstructured data (see Fig. 2), and the unstructured data include third-party data, Internet data, and data filled in and submitted by users.

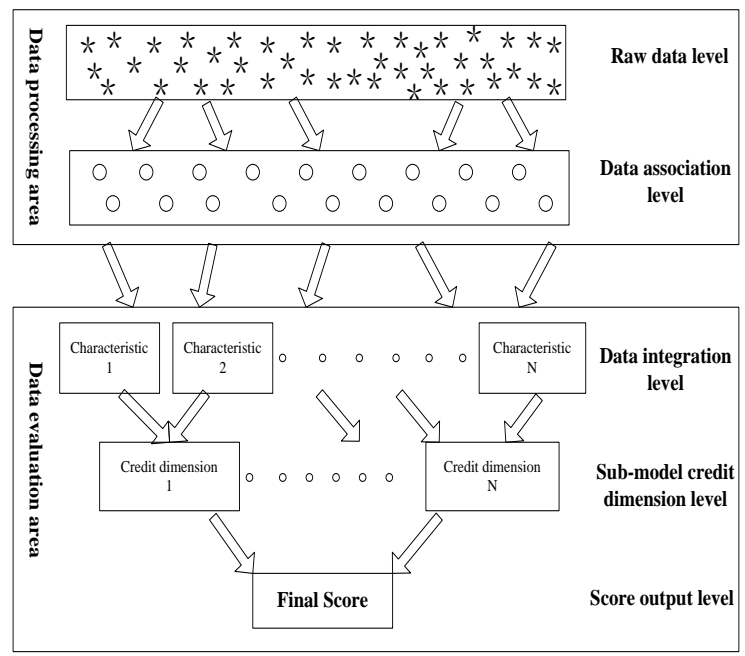

Fig. 1 Improved multilevel personal credit scoring model.

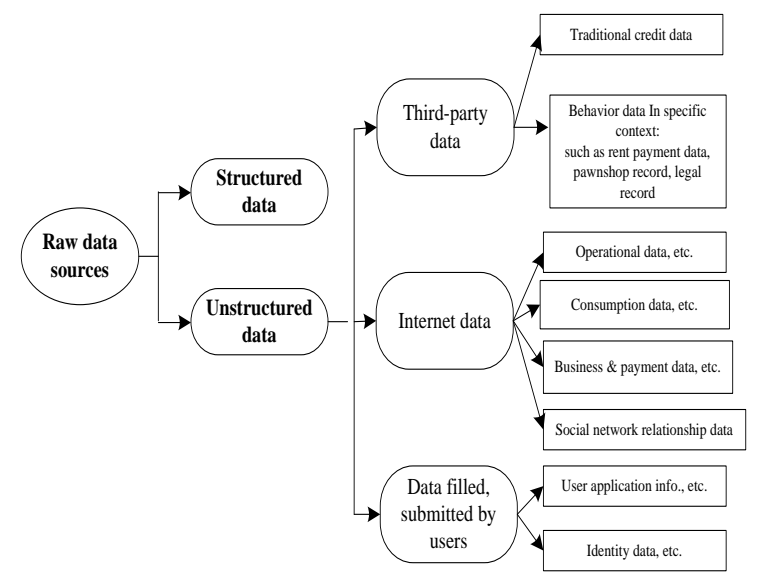

Fig. 2 Tree structure of raw data sources.

In those data, first, the most important data are the thirdparty data purchased or exchanged for credit assessment, including traditional credit data and behavior data in specific context; second, it is the Internet data, such as operational data, consumption data, and payment data. Those data can dig out the location information, personality and behavioral characteristics of users, in favor of risk assessment. Furthermore, social network relationship data are also a major important data source; third, it is the data filled in and submitted by users, such as the details indicating the identity of users. The application of all these nontraditional unconventional data is the main feature to distinguish from the traditional credit methods. On one hand, it inherits the decision variables of the traditional credit system to in-depth mine out the history of credit objects. On the other hand, it incorporates other factors of affecting credit levels of users to achieve the high degree of depth and breadth integration for data. In this case, big data credit is to realize all offline information to be online, reflecting the specificality and uniqueness of credit 
since the applicant initiates a service request, confirms authorization, and then starts a credit investigation [11].

The second level is a data association level where this model is to select the reasonable features out of full sample data rather than random sample data, to seek the correlation among them, to clarify their variable relationship, and to convert the data variables into the useful formats. Discontinuous or missing data items may cause traditional credit model unable to be applied. The big data fuzzy correlation technology goes beyond the traditional constraints of data accuracy, even processing and analyzing fragmented information and incomplete data streams [12]. As American Turbo Financial Group advocates to focus on the correlation among all data in stead of cause and effect in the analysis of big data credit, the information such as IP address, computer brand, and playing games or not is quite important in the credit assessment. Moreover it considers that all information given by users is useful, even lies, concealment, and wrong information, can reflect a person's critical information [13].

The third level is a data integration level in which this model transforms tens of thousands of data into variables to reintegrate those larger measurement indexes and to describe a certain characteristics of an applicant on the basis of data correlation, such as sincerity degree, default probabilities, credit risk and ability to repay. Big data credit analyzes and evaluates the credit history of applicants via specialized credit evaluation system and quantitative indicators [14], and can complete data retrieval, data filtering, and effective data integration in a short period of time.

The fourth level is a sub-model credit dimension level in which those larger measurement indexes in the third level are input into different separate variable analysis sub-models to process, and each sub-model is on behalf of a credit dimension. This requires that only by fully investigating the relevance between clues behind applicant behaviors can it provides in-depth and effective data analysis services. The more accurate and comprehensive the credit dimensions are, the more reliable the conclusions become.

The fifth level is a score output level where a separate conclusion of each sub-model is integrated together to arrive at its own independent credit score, contributing to a ratio of score, and to ultimately reach an independent synthesized score. The unstructured data are capable of mapping out behavorial characteristics, social characteristics, and psychological characteristics and other aspects of the applicants, and those data to be able to truly reflect personal credit status account for the larger weight proportion in the improved personal credit scoring model.

This model relies on the big data analysis and mining technologies to carry out the processing and evaluation on data. As matters stand presently, those technologies have been mature in China. It can dig deeper for more user credit information out of multiple data sources. A disruptive basic idea of this improved model is that it is possible to make "all data for credit" through those technologies. The massive and seemingly useless data are transformed into credit data after undergoing the procedures of cleansing, matching, integration, and mining. In this case, the efficiency and accuracy of credit assessment is improved to a certain extent, the correlation analysis directed against full sample data is more accurate, faster, more visual, and more objective, thus fundamentally promoting the development of small and micro financial services.

\section{Conclusion}

This paper verifies that the products and services provided by Ant Financial Services have the characteristics of disruptive innovation. Sesame Credit becomes one of the key links for Ant Financial Services to achieve disruptive innovation. As can be seen from the current scoring effects shown in the open beta, this paper reveals that there are some certain problems in Sesame Credit, and proposes the improved two-area five-level personal credit scoring model after more comprehensive analysis and consideration. This model, by virtue of new IT technologies represented by cloud computing and big data, processes a mass of multidimensional raw data through layers of weighted integration. It can ultimately reach more accurate credit scores for small and micro and individual customers that have not been covered by the traditional credit means, in line with the development trend that in the era of big data, the new credit assessment system more focuses on horizontal expansion and application of the current information of users.

\section{References}

[1] Shiyu Liu, China's Financial Stability Report 2014. People's Bank of China, http://www.cccity.cc/loan/2014/0430/34455.html, 2014.

[2] Yun Liu, Ruibo Zhu, "Internet finance, small and micro enterprise financing and credit system deepening," Credit Reference, no.2, pp. 78$88,2014$.

[3] Xiansheng Chao, How to Increase Sesame Credit Score, http://www.dib66.com/industryNews-2075-11.html, April 2015.

[4] Xiu Hu, Sesame Credit Open beta, Accuracy to be Improved, http://finance.jrj.com.cn/2015/02/10090118843942.shtml, February 2015.

[5] Christensen, C. M., \& Raynor, M. E., The Innovator's Solution, Harvard Business School Press. Boston: MA, pp. 67-75, 2003.

[6] Christensen, C.M., The innovator's dilemma: When new technologies cause great firms to fail, Harvard Business School Press, Boston: MA, 1997.

[7] Markides, C., "How disruptive will innovation from emerging markets be," Sloan Manag. Rev, vol. 54(1), pp. 22-25, 2012.

[8] Jiang Lin, "The review of FICO system in the U.S," Business Research, no.20, pp. 81-84, 2006.

[9] Xinhai Liu, "Big data credit application and enlightenment-a case study of American Internet finance company Zest Finance," Tsinghua Financial Review, pp. 93-98, 2014.

[10] Ping Cai, Xing Liang, Central Bank's Decisive Role in Credit, http://sxdsb.voc.com.cn/article/201502/201502050947067092002.html, Feb. 2015.

[11] Zhen Li, "Internet finance credit model: economic analysis, application study and judgment, and improved framework," Social Sciences in Ningxia, no.1, pp. 79-85, 2015.

[12] Ping Lin, "Considerations on credit market development in China under big data background," South China Finance, no.11, pp. 7-12, 2014.

[13] Ruixin Lu, "China credit opportunity and challenge in big data era," Financial Theory and Practice, no.2, pp. 103-107, 2015.

[14] Zhen $\mathrm{Li}$, "Big data credit: realistic application, dilemma and law perfect logic," Hainan Finance, no.1, pp. 5-9, 2015. 